\title{
Robust Adaptive PID Controller for a Class of Uncertain Nonlinear Systems: An Application for Speed Tracking Control of an SI Engine
}

\author{
Tossaporn Chamsai, ${ }^{1}$ Piyoros Jirawattana, ${ }^{2}$ and Thana Radpukdee ${ }^{1}$ \\ ${ }^{1}$ Department of Industrial Engineering, Khon Kaen University, Khon Kaen 40002, Thailand \\ ${ }^{2}$ Department of Mechanical Engineering, Khon Kaen University, Khon Kaen 40002, Thailand \\ Correspondence should be addressed to Thana Radpukdee; rthana@kku.ac.th
}

Received 12 October 2014; Accepted 25 February 2015

Academic Editor: Kacem Chehdi

Copyright (C) 2015 Tossaporn Chamsai et al. This is an open access article distributed under the Creative Commons Attribution License, which permits unrestricted use, distribution, and reproduction in any medium, provided the original work is properly cited.

\begin{abstract}
The sliding mode control (SMC) technique with a first-order low-pass filter (LPF) is incorporated with a new adaptive PID controller. It is proposed for tracking control of an uncertain nonlinear system. In the proposed control scheme, the adaptation law is able to update the PID controller online during the control process within a short period. The chattering phenomenon of the SMC can be alleviated by incorporation of a first-order LPF, while the robustness of the control system is similar to that of the sliding mode. In the closed-loop control analysis, the convergence condition in the reaching phase and the existence condition of the sliding mode were analyzed. The stability of the closed-loop control is guaranteed in the sense of Lyapunov's direct method. The simulations and experimental applications of a speed tracking control of a spark ignition (SI) engine via electronic throttle valve control architecture are provided to verify the effectiveness and the feasibility of the proposed control scheme.
\end{abstract}

\section{Introduction}

The presence of uncertain nonlinearity in physical systems has been extensively studied because most of the real systems are rather complex dynamical nonlinear with large uncertainties which can affect inaccuracy and poor robustness of the control system. To do this, numerous control schemes have been developed; for example, sliding mode control [1$3]$, intelligent control $[4,5]$, feedback linearization [6], and adaptive control [7-9].

On the other hand, due to its simplicity in architecture and simple design, the proportional-integral-derivative (PID) control is acceptable and has been extensively applied in many practical applications. The key for designing a high capability of PID controller depends on the determination of the PID gain parameters which should be properly adjusted, and this has led to the developments for self-tuning methods of the three parameters of the PID controller. Recently, adaptive control techniques are generally applied for onlinetuning of the PID controller. The flexibility of the PID tuning lies in the determination of the basic PID gains that can be adjusted online according to adaptation laws and using the error signal in order to realize the online adjustable gains during a control procedure [10-13]. However, the adaptive control strategy is capable of handling only constant parametric uncertainty, inadequate robustness for against external disturbance, and an accurate system model that is required [14].

The sliding mode control (SMC) method is one of the control strategies to dominate the parametric uncertainties and external disturbances, while the control principle is without precise system model information [15-18]. Nevertheless, if the sliding mode exists, the chattering phenomenon is the main obstacle for SMC application [19-21]. In much research work, alleviations chattering phenomenon of the sliding mode incorporated with a low-pass filter has been studied [22-26] because it can make a compromise between the alleviation of the chattering and the control accuracy. Incorporation of the SMC with closed-loop filtering is capable to realize the acquisition of control signal and 
the approximation of disturbances [24], while the robustness is similar to that of the sliding mode.

In this study, the SMC with a first-order LPF is incorporated with a new adaptive PID controller. It is proposed for perfect tracking control tasks of uncertain nonlinear systems. In the proposed control scheme, the PID controller is adjusted during the control procedure according to the adaptation laws, while the chattering of the control signal can be alleviated by the first-order LPF. The stability of the closedloop control can be guaranteed in the sense of Lyapunov's direct method [27, 28]. The effectiveness and the feasibility of the proposed control scheme are assessed in the problem of a speed tracking control of a spark ignition (SI) engine via electronic throttle valve control architecture. Interest is due to the delay of the intake manifold filling dynamic and the induction-power delay is the drawback in practice for engine speed control through the throttle valve regulation method $[29,30]$. Furthermore, the engine system is a rather complex mechanism, multiactuation, and largely uncertain nonlinearity phenomena which are present in the engine mechanism [31]. Therefore, the engine speed control is a well-known challenge in the problem of uncertain nonlinear control systems [32-34].

Increasing transient performance and tracking accuracy of speed responses are usefulness during acceleration of the vehicle at any operating condition, especially in the transition mode of the hybrid operating system of hybrid vehicles [35, 36]. The goal of the engine speed control resulting from the speed response is to be able to track a desired speed at any operating condition [37], especially at the transient-state that has significant effects on optimizing the maneuverability of an engine speed control. High accuracy of speed tracking control leads to the achievement of an optimal engine operating point for other applications. In addition, increased engine performance, reduced fuel consumption, and exhaust emission are other benefits of an optimized engine speed control $[38,39]$.

The remainder of this paper is organized as follows. Firstly, we present the controller design and closed-loop control analysis. In Section 3, a description of the engine speed control model is presented. In Section 4, the simulations and experimental results are presented to verify the effectiveness of the development control approach. Finally, the research conclusions are presented.

\section{Controller Design and Closed-Loop Control Analysis}

2.1. System Formulation. In an engine system, the two firstorder dynamic elements which are rotational dynamics and the manifold filling dynamics behave as a second-order system [40]. However, the system order can be reduced due to substitution of the engine torque as described by the meanvalue method [41] into the first-order crankshaft rotational dynamics from Newton's law. Thus, for simplicity, this work realizes the system to be a first-order uncertain nonlinear system, satisfying uncoupling and matching conditions [28, 40]. It can be described in a canonical form as

$$
\begin{gathered}
\dot{\mathbf{x}}(t)=\mathbf{f}(\mathbf{X}, t)+\mathbf{B}(\mathbf{X}, t) \mathbf{u}(t)+\mathbf{B}(\mathbf{X}, t) \boldsymbol{\eta}(\mathbf{X}, t), \\
\mathbf{x}\left(t_{0}\right)=\mathbf{x}_{0},
\end{gathered}
$$

where $\dot{\mathbf{x}}=\left[\dot{x}_{1}, \dot{x}_{2}, \ldots, \dot{x}_{m}\right]^{T} \in R^{m}$ is the first-order of the state vector, $t \in R$ is time, $\mathbf{f}(\mathbf{X}, t)=\left[f_{1}, \ldots, f_{m}\right]^{T} \in R^{m}$ is the known nonlinear function, $\mathbf{X}=\left[x_{1}, \ldots, x_{m}\right]^{T} \in R^{m}$ is the global state vector for the nonlinear square system, $m$ is the number of independent coordinates of $x_{i}, i=1, \ldots, m$, $\mathbf{u}(t)=\left[u_{1}, \ldots, u_{m}\right]^{T} \in R^{m}$ is the control input, $\boldsymbol{\eta}(\mathbf{X}, t)=$ $\left[\eta_{1}, \ldots, \eta_{m}\right]^{T} \in R^{m}$ is the uncertain element that presents only in the highest order of the system, and $\mathbf{B}(\mathbf{X}, t)=\left[b_{i j}\right] \in R^{m \times m}$, $i, j=1, \ldots, m$, is the control gain distribution matrix which is positive definite in all arguments. The aim is to force the system state $\mathbf{x}$ to reach the desired state $\mathbf{x}_{d}$ so that the error $\tilde{x}_{i}=x_{i}-x_{i d} \rightarrow 0, i=1, \ldots, m$. Not only does a control law have to steer the response to the desired value, but it must have the ability to overcome a system's uncertainties also.

In the work of $\mathrm{Xu}$ et al. [24], uncertainties can be estimated by adding a second low-pass filter; as a result, the switching gain is reduced to the minimum level, while the first low-pass filter smooths out the switching control. However, during the filter's reaching phase, there are no control inputs from both low-pass filters and a feed forward term from an equivalent control may not have the capability to override the uncertainties. If another control input, during the reaching phase, can be adjusted suitably, better transient control can be achieved. The assumptions below are made for control law derivation in the next section.

Assumption 1. The functions $\mathbf{f}(\mathbf{X}, t), \mathbf{B}(\mathbf{X}, t)$, and $\boldsymbol{\eta}(\mathbf{X}, t)$ are continuous in $\mathbf{X}$ for all $t$ and continuously differentiable.

Assumption 2. The uncertainties are within the range space of the control distribution matrix $\mathbf{B}(\mathbf{X}, t)$ and uncertainty variation does not affect the control direction.

Assumption 3. The estimated control distribution matrix $\widehat{\mathbf{B}}(\mathbf{X}, t)$ is invertible and continuously dependent on parametric uncertainty [28].

Assumption 4. Let $\mathbf{B}(\mathbf{X}, t) \boldsymbol{\eta}(\mathbf{X}, t)$ be upper bounded by $\|\mathbf{B}(\mathbf{X}, t) \boldsymbol{\eta}(\mathbf{X}, t)\| \leq M_{o}$ and $d(\mathbf{B}(\mathbf{X}, t) \boldsymbol{\eta}(\mathbf{X}, t)) / d t$ upper bounded by $\|d(\mathbf{B}(\mathbf{X}, t) \boldsymbol{\eta}(\mathbf{X}, t)) / d t\| \leq M_{d}$, where $M_{o}$ and $M_{d}$ are known constants.

Assumption 5. The input matrix is bounded by $0<b_{\min } \leq$ $\|\mathbf{B}(\mathbf{X}, t)\| \leq b_{\max }$ and its derivative is upper bounded by $\|d(\mathbf{B}(\mathbf{X}, t)) / d t\| \leq b_{d}$, where $b_{\min }, b_{\max }$, and $b_{d}$ are known constants.

2.2. Closed-Loop Control Design. To design the control law, a definition of the sliding function similar to the work of Slotine and $\mathrm{Li}[28]$ is adapted to the first-order system. The sliding function can be made on each state as

$$
s_{i t}\left(x_{i}(t)\right)=\tilde{x}_{i}, \quad i=1, \ldots, m .
$$




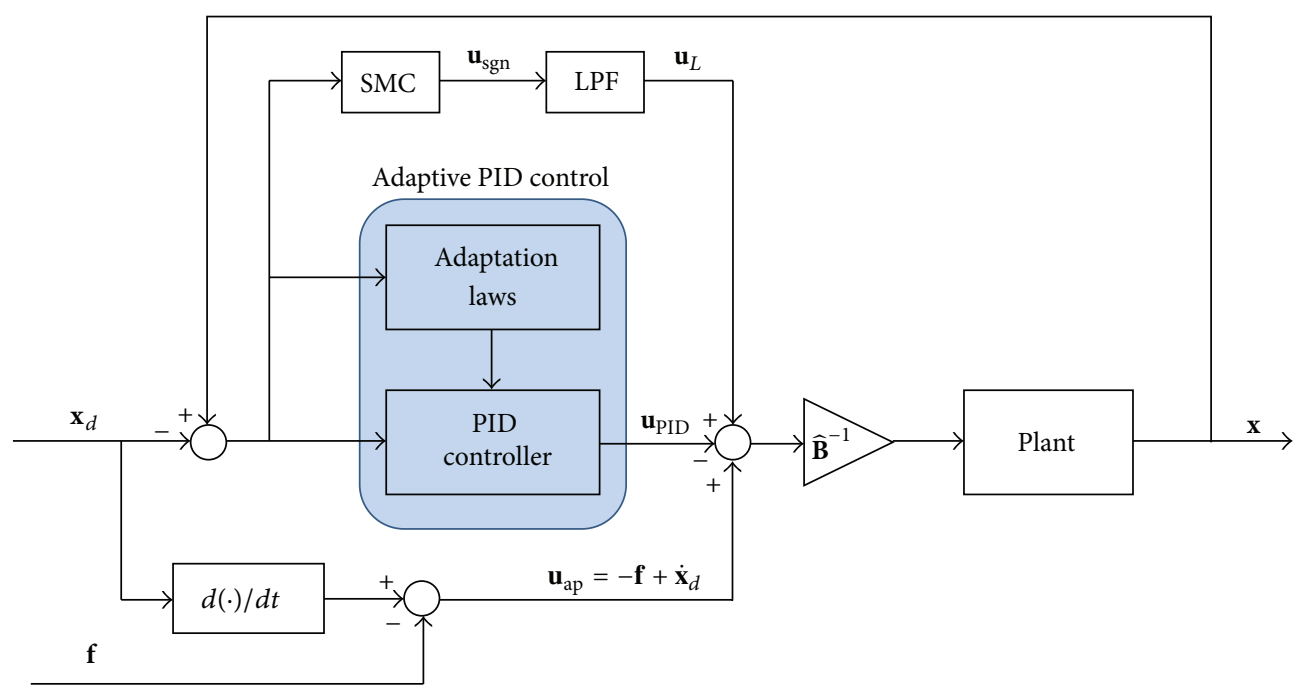

FIgURE 1: A schematic diagram of the proposed controller (LPFSMC and Adaptive PID technique).

Then, the $m$-dimensional sliding function and its first derivative for the system in (1) can be expressed as

$$
\begin{aligned}
& \mathbf{s}_{t}(\mathbf{x})=\mathbf{x}-\mathbf{x}_{d}, \\
& \dot{\mathbf{s}}_{t}(\mathbf{x})=\mathbf{C}\left(\dot{\mathbf{x}}-\dot{\mathbf{x}}_{d}\right),
\end{aligned}
$$

where $\mathbf{s}_{t}(\mathbf{x})=\left[s_{1 t}, \ldots, s_{m t}\right]^{T}$ has components satisfying the sliding function stated earlier and $\mathbf{C}$ is a positive constant coefficient $m \times m$ matrix with full row rank. Its argument is a gradient vector of the sliding function [42] which is unity in each sliding surface due to the first-order system.

From Figure 1, the control input is

$$
\mathbf{u}(t)=\widehat{\mathbf{B}}^{-1}\left[\mathbf{u}_{\mathrm{ap}}-\left(\mathbf{u}_{\mathrm{PID}}-\mathbf{u}_{L}\right)\right],
$$

where $\mathbf{u}_{L}$ is the low-frequency pass filter signal which is a result of a first-order low-pass filter of the switching signal $\mathbf{u}_{\mathrm{sgn}}=-\mathbf{M}_{s} \operatorname{sgn}(\mathbf{s}) ; \operatorname{sgn}\left(s_{i}\right)=\left\{\begin{array}{c}+1 \text { if } s_{i}>0 \\ -1 \text { if } s_{i}<0\end{array}\right.$. Let $\mathbf{M}_{s}=$ $\operatorname{diag}\left(M_{o}\left|s_{i t}\right|\right), \operatorname{sgn}(\mathbf{s})=\left[\operatorname{sgn}\left(s_{1}\right), \ldots, \operatorname{sgn}\left(s_{m}\right)\right]^{T}$, and $\mathbf{u}_{\mathrm{PID}}$ denote the control signal of the adaptive PID tuning. $\mathbf{u}_{\mathrm{ap}}$ is an approximation of the control input that neglects the last term of the RHS of (1) and is the unit matrix. Therefore, an approximation can be obtained similar to the idea of the equivalent control input [15] which is

$$
\mathbf{u}_{\mathrm{ap}}=-\mathbf{f}+\dot{\mathbf{x}}_{d} .
$$

For the solution of $\mathbf{u}_{L}$, it can be obtained by

$$
T_{f} \dot{\mathbf{u}}_{L}+\mathbf{u}_{L}=\mathbf{u}_{\text {sgn }},
$$

where $T_{f}$ is the cut-off frequency. The LPF is activated at the time of $t=t_{\text {reach }}$ with the zero initial condition of $\mathbf{u}_{L}\left(t_{\text {reach }}\right)=$ 0 and given $t_{\text {reach }}$ is the reaching time. For $\mathbf{u}_{\mathrm{PID}}$, it can be obtained by

$$
\mathbf{u}_{\mathrm{PID}}=\mathbf{k}_{P} \mathbf{s}+\mathbf{k}_{I} \int \mathbf{s} d t+\mathbf{k}_{D} \dot{\mathbf{s}},
$$

where $\mathbf{k}_{P}=\operatorname{diag}\left(k_{P i}\right)$ is the proportional gain, $\mathbf{k}_{I}=\operatorname{diag}\left(k_{I i}\right)$ is the integral gain, and $\mathbf{k}_{D}=\operatorname{diag}\left(k_{D i}\right)$ is the derivative gain. $k_{P i}, k_{I i}$, and $k_{D i} \in R^{+}$which are not equal to zero.
2.2.1. Reaching Phase Analysis. This section presents a description of the reaching time calculation for the closedloop control system by the proposed control law in (4). For the reaching time $\left(t_{\text {reach }}\right)$, the first-order LPF will be activated when $t=t_{\text {reach }}$ with zero initial condition of the filter input signal. Consequently, $\mathbf{u}_{L}\left(t_{\text {reach }}\right)=0$ for $0 \leq t \leq t_{\text {reach }}$. Therefore, the control input during the reaching phase is obtained by

$$
\mathbf{u}=\widehat{\mathbf{B}}^{-1}\left[\mathbf{u}_{\mathrm{ap}}-\mathbf{u}_{\mathrm{PID}}\right] .
$$

Note that Assumption 5 can be extended to the gain margin concept [28] for adaptation law derivation. For stability in the reaching phase, Lyapunov's theorem is chosen to prove the stability of the controller and the errors can converge to the sliding surface if $\mathbf{u}$ is constructed to achieve the first derivative of the Lyapunov function candidate $\dot{\mathbf{V}}<0$. Choose the Lyapunov function candidate of $\mathbf{V}>0$. Therefore, $\mathbf{V}$ at the reaching phase can be described as

$$
\mathbf{V}=\frac{1}{2} \mathbf{s}^{T} \mathbf{s}+\frac{1}{2}\left(\mathbf{k}_{P}^{T} \mathbf{k}_{P}+\mathbf{k}_{I}^{T} \mathbf{k}_{I}+\mathbf{k}_{D}^{T} \mathbf{k}_{D}\right) .
$$

Then, the derivative of the Lyapunov function, (9), can be rewritten as

$$
\dot{\mathbf{V}}=\mathbf{s}^{T} \dot{\mathbf{s}}+\left(\mathbf{k}_{P}^{T} \dot{\mathbf{k}}_{P}+\mathbf{k}_{I}^{T} \dot{\mathbf{k}}_{I}+\mathbf{k}_{D}^{T} \dot{\mathbf{k}}_{D}\right) .
$$

To find the condition satisfying the Lyapunov stability, the first derivative of the sliding function $\dot{\mathbf{s}}$ must be substituted into (10). It can be derived by

$$
\begin{aligned}
\dot{\mathbf{s}}= & \mathbf{C}\left(\dot{\mathbf{x}}-\dot{\mathbf{x}}_{d}\right) \\
= & \mathbf{C} \mathbf{f}+\mathrm{CB} \boldsymbol{\eta}-\mathbf{C} \dot{\mathbf{x}}_{d}+\mathbf{C B} \widehat{\mathbf{B}}^{-1}\left(-\mathbf{f}+\dot{\mathbf{x}}_{d}-\mathbf{u}_{\mathrm{PID}}\right) \\
= & \left(\mathbf{C} \mathbf{f}+\mathrm{CB} \boldsymbol{\eta}-\mathrm{CB} \widehat{\mathbf{B}}^{-1} \mathbf{f}\right)+\dot{\mathbf{x}}_{d}\left(\mathbf{C B} \widehat{\mathbf{B}}^{-1}-\mathbf{C}\right) \\
& -\mathrm{CB} \widehat{\mathbf{B}}^{-1} \mathbf{k}_{P} \mathbf{s}-\mathrm{CB} \widehat{\mathbf{B}}^{-1} \mathbf{u}_{\mathrm{ID}},
\end{aligned}
$$


where $\mathbf{u}_{\mathrm{ID}}=\mathbf{k}_{I} \int \mathbf{s} d t+\mathbf{k}_{D} \dot{\mathbf{s}}$. Equation (11) shows the fact that the control gain cannot be determined exactly. In the following, the gain margins concept [28] is adapted without loss of generality due to the uncoupling and matching conditions. From the concept, the gain estimation can be described by $\widehat{\mathbf{B}}=\operatorname{diag}(\widehat{b}), \widehat{b}=\sqrt{b_{\min } \cdot b_{\max }}$, and the bound of the control gain ratio can then be realized in the form $\beta^{-1} \leq\left\|\widehat{\mathbf{B}} \mathbf{B}^{-1}\right\| \leq \beta$ while $\beta=\sqrt{b_{\max } / b_{\text {min }}}$, and the initial value in each argument of the three gains $\left(\mathbf{k}_{P}, \mathbf{k}_{I}\right.$, and $\left.\mathbf{k}_{D}\right)$ of the PID portion is positive. Substituting (11) into (10) yields

$$
\begin{aligned}
\dot{\mathbf{V}}= & \mathbf{s}^{T}\left[\left(\mathbf{C} \mathbf{f}+\mathbf{C B} \boldsymbol{\eta}-\mathbf{C B} \widehat{\mathbf{B}}^{-1} \mathbf{f}\right)+\dot{\mathbf{x}}_{d}\left(\mathbf{C B} \widehat{\mathbf{B}}^{-1}-\mathbf{C}\right)\right] \\
& -\mathbf{s}^{T} \mathbf{C B} \widehat{\mathbf{B}}^{-1} \mathbf{k}_{P} s-\mathbf{s}^{T} \mathbf{C B} \widehat{\mathbf{B}}^{-1} \mathbf{u}_{\mathrm{ID}}+\mathbf{G},
\end{aligned}
$$

where $\mathbf{G}=\left(\mathbf{k}_{P}^{T} \dot{\mathbf{k}}_{P}+\mathbf{k}_{I}^{T} \dot{\mathbf{k}}_{I}+\mathbf{k}_{D}^{T} \dot{\mathbf{k}}_{D}\right)$, which is the adaptation term. For (12), if $\mathbf{k}_{p}$ is chosen to overcome a part of the uncertainties, the adaptation law in the last term $\mathbf{G}$ can be determined to eliminate the rest of them consequently. In order to compensate for the uncertainties in the reaching phase, the proportional gain $k_{P i}$ should satisfy equations below:

$$
\left\|\mathbf{k}_{P}\right\| \geq\left\|\left(\widehat{\mathbf{B}} \mathbf{B}^{-1} \mathbf{f}+\widehat{\mathbf{B}} \mathbf{B}^{-1} \mathbf{B} \boldsymbol{\eta}-\mathbf{f}\right)+\left(1-\widehat{\mathbf{B}} \mathbf{B}^{-1}\right) \dot{\mathbf{x}}_{d}\right\| .
$$

Then all arguments in the proportional gain are selected to satisfy

$$
\begin{aligned}
& k_{P i} \geq\left|\beta M_{o}+(1-\beta)\left(-f_{i}+\dot{x}_{i d}\right)\right|, \\
& k_{P i} \geq\left|\beta M_{o}\right|+\left|(1-\beta) u_{\text {iap }}\right| .
\end{aligned}
$$

Equations (13) to (15) correspond to the gain margin calculation method [28]. Even if the proportional term can be designed to cope with the first term in (12), its residual error still exists. Let the residual error be the difference between the first term and the second term of (12). It is bounded by a positive value $\Delta=\| \mathbf{s}^{T}\left[\left(\mathbf{C} \mathbf{f}+\mathbf{C B} \boldsymbol{\eta}-\mathbf{C B} \widehat{\mathbf{B}}^{-1} \mathbf{f}\right)+\mathbf{C}\left(\mathbf{B} \widehat{\mathbf{B}}^{-1}-1\right) \dot{\mathbf{x}}_{d}\right]-$ $\mathbf{s}^{T} \mathbf{C B} \widehat{\mathbf{B}}^{-1} \mathbf{k}_{P} \mathbf{s} \|$ due to a bounded control input. By adding the bound of the control gain ratio, (12) can be rewritten as

$$
\begin{aligned}
\dot{\mathbf{V}} \leq & -\Delta \mathbf{s}^{T} \mathbf{s}-\mathbf{s}^{T} \mathbf{C B} \widehat{\mathbf{B}}^{-1} \mathbf{k}_{I} \int \mathbf{s} d t-\mathbf{s}^{T} \mathbf{C B} \widehat{\mathbf{B}}^{-1} \mathbf{k}_{D} \dot{\mathbf{s}} \\
& +\mathbf{k}_{P}^{T} \dot{\mathbf{k}}_{P}+\mathbf{k}_{I}^{T} \dot{\mathbf{k}}_{I}+\mathbf{k}_{D}^{T} \dot{\mathbf{k}}_{D} \\
\leq & -\Delta \mathbf{s}^{T} \mathbf{s}-\beta \mathbf{s}^{T} \mathbf{C} \mathbf{k}_{I} \int \mathbf{s} d t-\beta \mathbf{s}^{T} \mathbf{C} \mathbf{k}_{D} \dot{\mathbf{s}} \\
& +\mathbf{k}_{P}^{T} \dot{\mathbf{k}}_{P}+\mathbf{k}_{I}^{T} \dot{\mathbf{k}}_{I}+\mathbf{k}_{D}^{T} \dot{\mathbf{k}}_{D} .
\end{aligned}
$$

Obviously, to satisfy the Lyapunov stability of the condition, $\dot{\mathbf{V}}<0$, and the adaptation law can be designed as $\dot{\mathbf{k}}_{P}=0$, $\dot{\mathbf{k}}_{I}=\beta \mathbf{s}^{T} \mathbf{C} \int \mathbf{s} d t$, and $\dot{\mathbf{k}}_{D}=\beta \mathbf{s}^{T} \mathbf{C} \dot{\mathbf{s}}$. Note that the proportional gain has a coupling effect with the sliding gain, which operates with the unity boundary layer width. Therefore, $\mathbf{k}_{P}$ does not need to be updated online. The adaptation gains $\left(\dot{\mathbf{k}}_{I}\right.$ and $\dot{\mathbf{k}}_{D}$ ) are capable of guaranteeing the stability only outside the bound of the control gain ratio $\beta$. This implies that this technique only offers a uniform ultimate boundedness response. Additionally, it is usual to have a solution when the control gain magnitude is unknown. Even if the control gain is known or adapted, the ultimate boundedness still occurs inside the vicinity around the sliding surface. Notice that at the beginning state, the integral and the derivative terms of the adaptation law may be arbitrary small, because the uncertainties at the beginning state can be compensated by $\mathbf{k}_{p}$. Consequently, (16) can be replaced by the adaptation law and the new expression of (16) becomes

$$
\dot{\mathbf{V}} \leq-\Delta \mathbf{s}^{T} \mathbf{s} .
$$

With the positive-initial value of the PID gains and the condition of (15) and the adaptation laws, the stability within the reaching phase can be guaranteed. The reaching time $\left(t_{\text {reach }}\right)$ can be obtained by

$$
t_{\text {reach }} \leq \frac{\left\|\mathbf{s}_{(t=0)}\right\|}{\Delta} .
$$

2.2.2. Existence of the Sliding Condition. The key issue of this section is to describe the sliding mode retention. For the existence conditions of the sliding mode at $t \geq t_{\text {reach }}$, the first-order low-pass filter (LPF) is activated and the switching signal is alleviated in turn. To describe the existence of the sliding condition, substitute the control law $\mathbf{u}(t)=\widehat{\mathbf{B}}^{-1}\left[\mathbf{u}_{\mathrm{ap}}-\right.$ $\left(\mathbf{u}_{\text {PID }}-\mathbf{u}_{L}\right)$ ]. Therefore, the derivative of the closed-loop $\mathbf{s}$ dynamic at $t \geq t_{\text {reach }}$ can be obtained by

$$
\begin{aligned}
\dot{\mathbf{s}}= & \left(\mathbf{C} \mathbf{f}+\mathrm{CB} \boldsymbol{\eta}-\mathrm{CB} \widehat{\mathbf{B}}^{-1} \mathbf{f}\right)+\mathrm{C}\left(\mathbf{B} \widehat{\mathbf{B}}^{-1}-1\right) \dot{\mathbf{x}}_{d} \\
& -\mathrm{CB} \widehat{\mathbf{B}}^{-1} \mathbf{k}_{P} \mathbf{s}-\mathbf{C B} \widehat{\mathbf{B}}^{-1} \mathbf{u}_{\mathrm{ID}}+\mathrm{CB} \widehat{\mathbf{B}}^{-1} \mathbf{u}_{L} .
\end{aligned}
$$

With the condition in (15), (19) can be rearranged as

$$
\begin{aligned}
-\mathrm{CB} \widehat{\mathbf{B}}^{-1} \mathbf{k}_{P} \mathbf{s}= & \dot{\mathbf{s}}-\left(\mathbf{C f}+\mathrm{CB} \boldsymbol{\eta}-\mathrm{CB} \widehat{\mathbf{B}}^{-1} \mathbf{f}\right) \\
& -\mathrm{C}\left(\mathbf{B} \widehat{\mathbf{B}}^{-1}-1\right) \dot{\mathbf{x}}_{d}+\mathrm{CB} \widehat{\mathbf{B}}^{-1} \mathbf{u}_{\mathrm{ID}}-\mathrm{CB} \widehat{\mathbf{B}}^{-1} \mathbf{u}_{L} .
\end{aligned}
$$

Multiplying (20) by $\left(\mathbf{C B} \widehat{\mathbf{B}}^{-1}\right)^{-1}$ yields

$$
\begin{aligned}
-\mathbf{k}_{P} \mathbf{s}= & \widehat{\mathbf{B}} \mathbf{B}^{-1} \\
\cdot & {\left[\mathbf{C}^{-1} \dot{\mathbf{s}}-\left(\mathbf{f}+\mathbf{B} \boldsymbol{\eta}-\mathbf{B} \widehat{\mathbf{B}}^{-1} \mathbf{f}\right)-\left(\mathbf{B} \widehat{\mathbf{B}}^{-1}-1\right) \dot{\mathbf{x}}_{d}\right.} \\
& \left.+\mathbf{B} \widehat{\mathbf{B}}^{-1} \mathbf{u}_{\mathrm{ID}}-\mathbf{B} \widehat{\mathbf{B}}^{-1} \mathbf{u}_{L}\right] .
\end{aligned}
$$

From the condition in (15), the sliding gain can be changed to be $\mathbf{M}_{s}=\operatorname{diag}\left(k_{P i}\left|s_{i t}\right|\right)$ and the output from the LPF can be satisfied by $T_{f} \dot{\mathbf{u}}_{L}+\mathbf{u}_{L}=-\operatorname{diag}\left(k_{P i}\left|s_{i t}\right|\right) \operatorname{sgn}(\mathbf{s})=-\mathbf{k}_{P} \mathbf{s}$. Therefore

$$
\begin{aligned}
T_{f} \dot{\mathbf{u}}_{L}+ & 2 \mathbf{u}_{L} \\
= & \widehat{\mathbf{B}} \mathbf{B}^{-1} \\
& \cdot\left[\mathbf{C}^{-1} \dot{\mathbf{s}}-\left(\mathbf{f}+\mathbf{B} \boldsymbol{\eta}-\mathbf{B} \widehat{\mathbf{B}}^{-1} \mathbf{f}\right)-\left(\mathbf{B} \widehat{\mathbf{B}}^{-1}-1\right) \dot{\mathbf{x}}_{d}+\mathbf{B} \widehat{\mathbf{B}}^{-1} \mathbf{u}_{\mathrm{ID}}\right] .
\end{aligned}
$$


As the reaching phase analysis, the control law in (8) and its adaptation law offer convergence regulation of the state. Intuitively, the sliding function $\mathbf{s}$ is bounded about the sliding surface $\mathbf{s}=\mathbf{0}$ due to imperfection of control action in practice. Thus, the derivative of the sliding function $\dot{s}$ will be bounded by the boundedness of $\|\mathbf{s}\|$ which also implies the integral of s converges to some limit [43]. Consequently, the RHS of (22) can be bounded and is rewritten by a residual matrix $\emptyset=\left[\emptyset_{1}, \ldots, \emptyset_{m}\right]^{T} \in R^{m}$. For each argument of the $\mathbf{u}_{L}$, the residual function $\emptyset_{i}, i=1 \cdots m$, can be interpreted as residual errors after the reaching phase, which satisfy

$$
T_{f} \dot{u}_{L i}+2 u_{L i}=\emptyset_{i}
$$

Given $\gamma=2 / T_{f}$ and $\varphi_{i}=\emptyset_{i} / T_{f},(23)$ is rewritten as

$$
\dot{u}_{L i}+\gamma u_{L i}=\varphi_{i}
$$

From (24), the bound on $\varphi_{i}$ can be interpreted into a bound on the filter output $u_{L i}$. Define the bound of $\varphi_{i}=\Phi_{i}$. The bound of the filter output $\left|u_{L i}\right|$ can be written as (25) which corresponds to [28]

$$
\left|u_{L i(t)}\right| \leq\left(\frac{\Phi_{i}}{\gamma}\right)\left(1-e^{-\gamma t}\right) .
$$

In which $u_{L i(t)}$ tends to $\Phi_{i} / \gamma[28]$ when $t \rightarrow \infty$. Thus,

$$
\left|u_{L i(t)}\right| \leq \frac{\Phi_{i}}{\gamma}
$$

Consider (26), if $T_{f}$ and $\beta$ are known, the residual uncertainties from the reaching phase can be compensated by $\mathbf{u}_{L}$. To consider the stability of the control system by using the input according to (4), (12) can be rewritten as

$$
\begin{aligned}
\dot{\mathbf{V}}= & \mathbf{s}^{T}\left[\left(\mathbf{C} \mathbf{f}+\mathbf{C B} \boldsymbol{\eta}-\mathbf{C B} \widehat{\mathbf{B}}^{-1} \mathbf{f}\right)+\mathbf{C}\left(\mathbf{B} \widehat{\mathbf{B}}^{-1}-1\right) \dot{\mathbf{x}}_{d}\right] \\
& -\mathbf{s}^{T} \mathbf{C B} \widehat{\mathbf{B}}^{-1} \mathbf{k}_{P} \mathbf{s}-\mathbf{s}^{T} \mathbf{C B} \widehat{\mathbf{B}}^{-1} \mathbf{u}_{\mathrm{ID}}-\mathbf{s}^{T} \mathbf{C B} \widehat{\mathbf{B}}^{-1} \mathbf{u}_{L}+\mathbf{G} .
\end{aligned}
$$

Notice that the adding of the $\mathbf{u}_{L}$ leads to uncertain of negative definite on the Lyapunov function derivative. In order to stabilize (27), the proportional portion has to take the output from the LPF and the bound of uncertainty and its derivative into account. By defining $M_{t}=M_{0}+M_{d}+\left\|\mathbf{u}_{L}\right\|$, the modified proportional gain for each sliding surface can be $k_{P i} \geq\left|\beta M_{t}\right|+\left|(1-\beta) u_{i \text { ap }}\right|$. And together with the adaptation laws defined in the previous section, $\dot{\mathbf{V}}$ in (27) is negative definite $(\dot{V}<0)$. The sliding motion can be guaranteed for $t \in\left[t_{\text {reach }}, \infty\right)$ under the conditions stated earlier.

\section{Description of the Engine Speed Control Modeling}

As stated earlier, a key step of the development control scheme is based on the robust control techniques in which the approach has the ability to neglect the conservatism and the need for precise modeling [44]. In addition, the development of an exact model for a real engine system is difficult, because some parameters in the mathematical model cannot be obtained exactly, and the real plant is affected by the complexity of its uncertain nonlinearity [45]. Consequently, the system modeling in this work was linearized through the nominal transfer function of the real plant as the form of

$$
x(s)=G_{\mathrm{ta}}(s) e^{-T_{D} s} u_{\mathrm{ta}}(s)+G_{\mathrm{sa}}(s) e^{-T_{D} s} u_{\mathrm{sa}}(s),
$$

where $x(s)$ is the output, the time delay is $T_{D}, u_{\mathrm{ta}}(s)$ is the control input for a throttle actuator, and $u_{\mathrm{sa}}(s)$ is the control input for the spark advance system. $G_{\mathrm{ta}}(s)$ and $G_{\mathrm{sa}}(s)$ are the linearized models by $u_{\mathrm{ta}}(s)$ and $u_{\mathrm{sa}}(s)$, respectively. Note that the symbol $s$ in this section denotes the complex argument of the Laplace transform which is not the sliding function.

Although the conventional relevant engine dynamic for engine speed control depends on the coordination between the throttle actuator and the spark advance system; for the assessment in this work, we have designed a controller that aims to control only the throttle actuator, while the spark advance system is handled by conventional controller of the engine system. Therefore, the system modeling in this work can be obtained by an adjustment of the throttle opening position in degrees, which is directly controlled with a DC motor that is excited by the feed-forward control signal in DC-voltage as an input and the crankshaft speed in revolutions per minute (rpm) as an output. Consequently, the linearization model at speed $900 \mathrm{rpm}$ can be approximated in the transfer function form as

$$
G(s)=\frac{45 s^{2}+44 s+90}{s^{3}+1.5 s^{2}+2.5 s+1},
$$

where $G(s)$ is the transfer function of the real plant which has units of revolutions per minute (rpm). From the rough identifications of (29), it is the third-order with relative degree one and the system is BIBO stable because all poles are located on the left-hand side (LHS) of the $s$-plane. In addition, for the reason of low-speed control test (900 rpm), it is sensitive to any uncertain nonlinearities and external disturbances. Therefore, the implementation of speed control in the low-speed region is more difficult than in the highspeed control region. Furthermore, on average 30 percent of fuel consumption in urban city driving is spent at the idle speed range [46]. As a consequence, increasing the performance of the low-speed control is able to increase fuel economy and performance of the engine operation at any operating condition [32].

For simplicity, to make the engine speed response as the canonical form of (1), the rough identification model of (29) can be simplified to the first-order transfer function as follows:

$$
G(s)=\frac{44.5}{s+0.493} .
$$

To make clear the acceptability of (30), the bode plot and the step response comparison between (29) and (30) are demonstrated in Figure 2. The results make clear that the first-order transfer function in (30) can be employed in the performance assessment of the proposed controller design in 

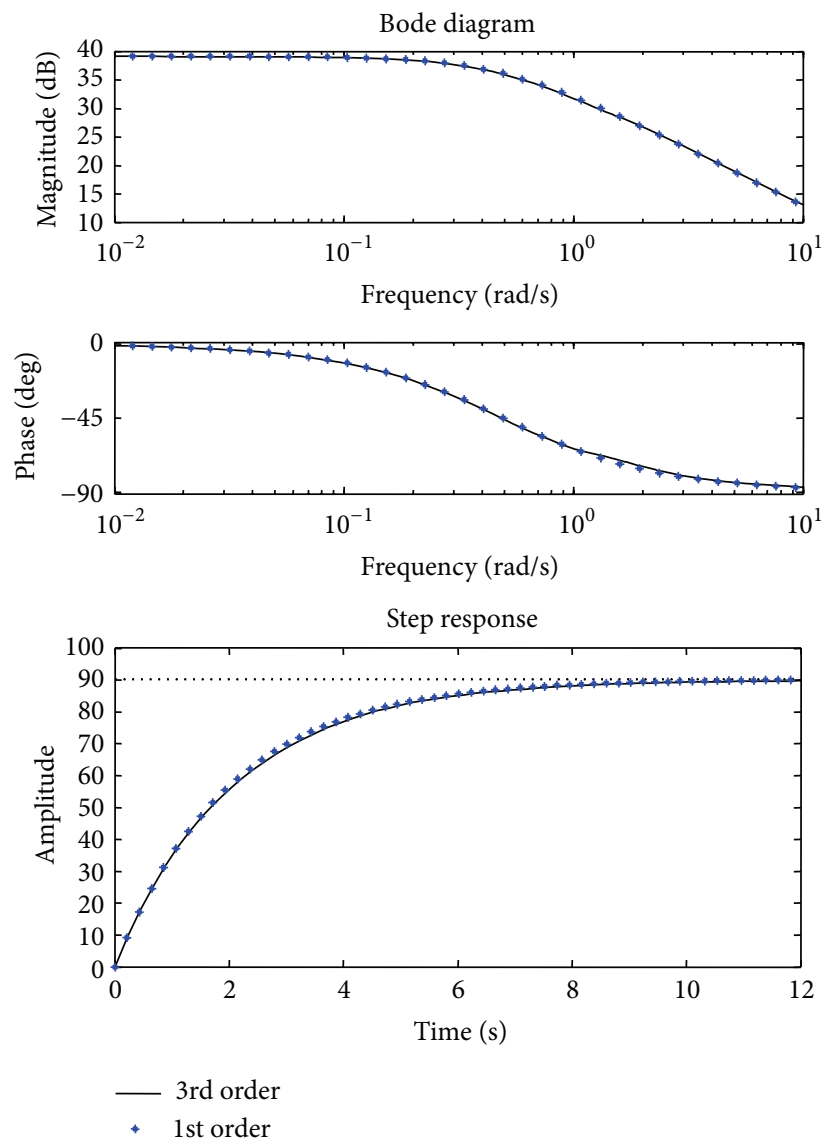

FIGURE 2: The validation of the 1st-order model.

the simulations and (30) can be expressed as the time-domain differential equation as follows:

$$
\dot{x}=-0.493 x+44.5 u,
$$

where $x$ is the speed output and $u$ is the input.

\section{Illustrative Examples}

4.1. Simulation Verification. For the simulation verification, the system modeling of (31) is used in order to assess the performance of the proposed control scheme (LPFSMC and Adaptive PID) that is performed via MATLAB-Simulink programming with a sampling period of $1 \mathrm{~ms}$. The performance of the proposed controller is compared with different control techniques, which are the PID control technique and the SMC technique. The specific control parameters are chosen such that the sliding gain of the proposed control scheme and the conventional SMC is $\mathbf{M}_{t}=10$, the cut-off frequency of the first-order LPF is $T_{f}=4$, while the setting control parameters of the PID controller are obtained by the Ziegler-Nichols tuning method.

Figure 3(a) demonstrates the response results of the proposed control scheme which has a small rise time and setting time and higher tracking accuracy than other control techniques (PID controller and SMC). It demonstrates that the proposed adaptation law is capable of updating the PID controller online during the control process within a short period. Furthermore, the proposed control scheme can provide optimal control input rapidly and has smooth control input which is achieved by the cut-off frequency property of the LPF (see Figure 3(b)).

Figure 3(c) shows the error comparison among the different controllers; as the results, the errors from the proposed control scheme can approach zero faster than other control techniques and it has lower chattering than the SMC technique. Note that although the chattering of the output response, control input, and the errors of the PID controller does not appear, the results (see Figure 3) reveal that its response has higher rise-time, high-overshoot, and longer setting time, which are not satisfactory from the viewpoint of a control system.

4.2. Practical Experiment. In this section, we demonstrate the efficiency of the proposed control scheme in the real system. The experimental technical data are shown in Table 1. In our setup, the functional block diagrams of the apparatus used in the experiments are illustrated in Figure 4 which is used for performance assessment of the proposed control scheme. The system in Figure 4 consists of five main parts, which are the controller unit, electronic throttle valve control unit (ETC), spark-ignition (SI) engine system, the power train system, 


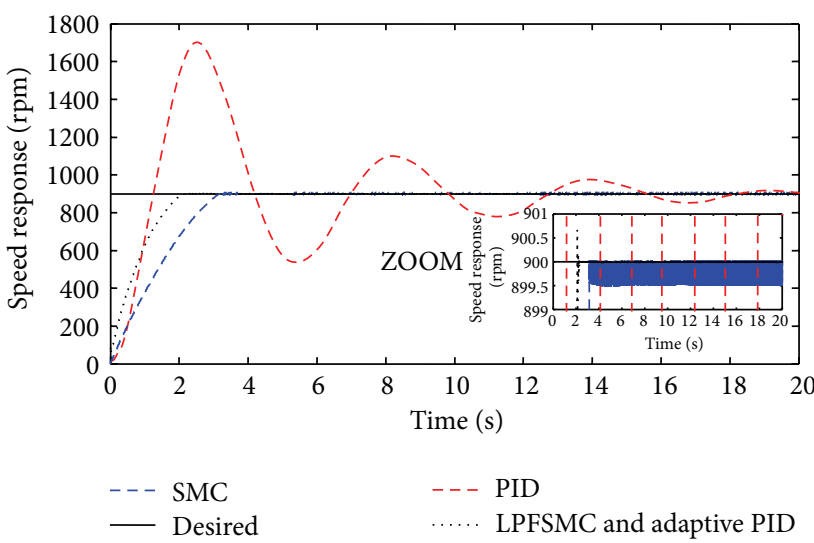

(a)

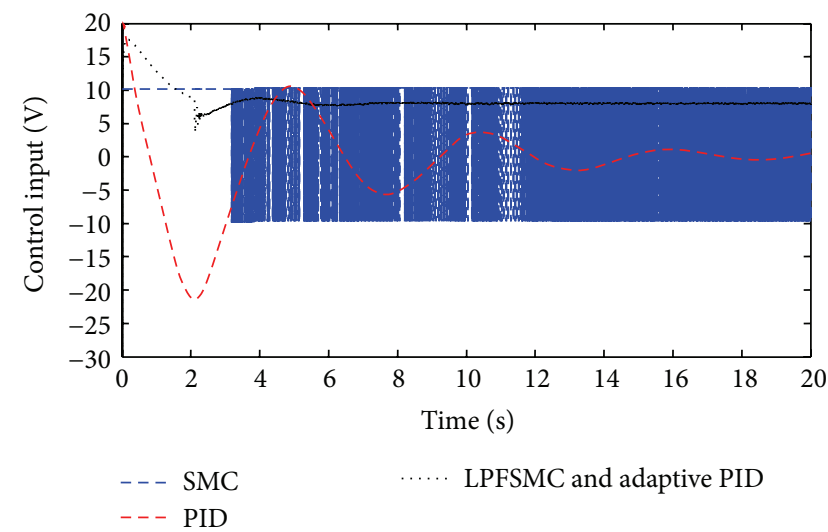

(b)

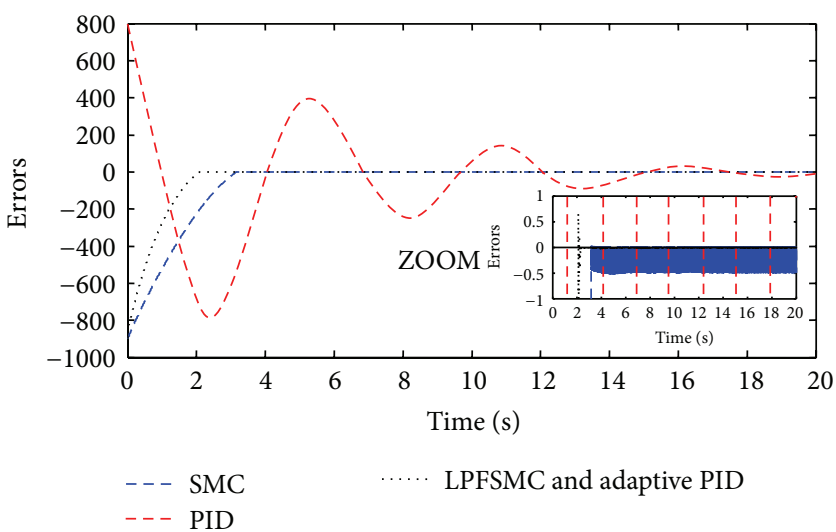

(c)

FIGURE 3: Comparison of simulation results among different control techniques: (a) the output response; (b) the control inputs; (c) the errors.

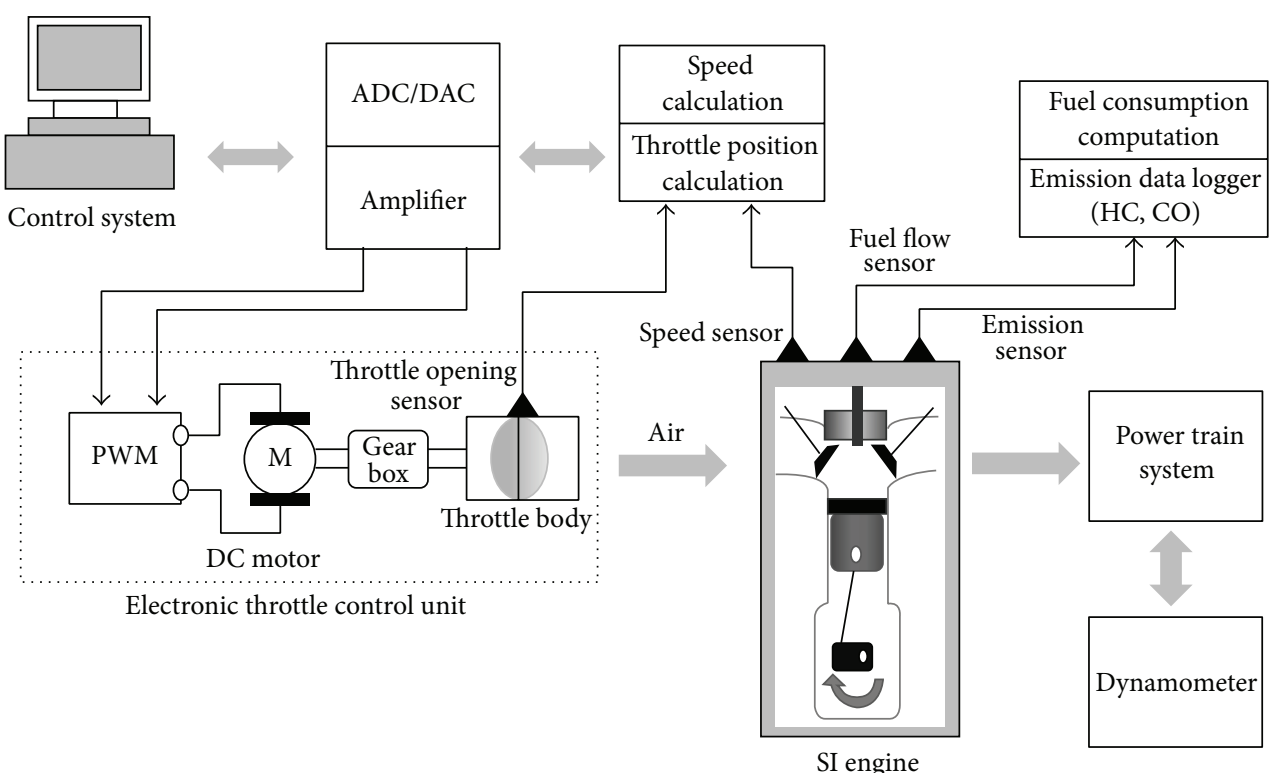

FIGURE 4: Schematic diagram of the experiment. 

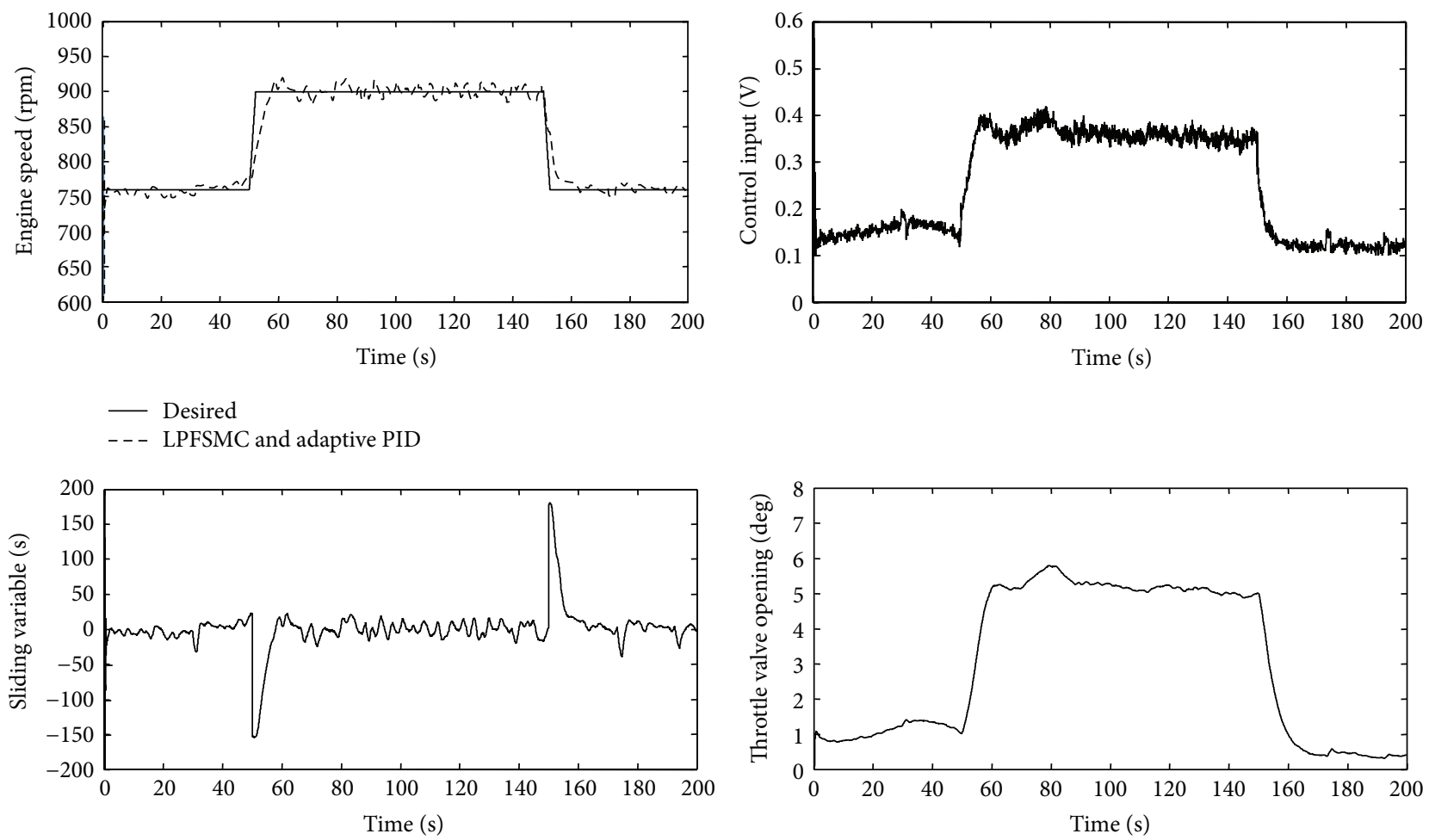

FIGURE 5: Experimental results of the proposed controller (LPFSMC and Adaptive PID technique).

TABLE 1: Experimental technical data.

\begin{tabular}{ll}
\hline Item & Value \\
\hline $\begin{array}{l}\text { SI engine (4 cylinders, } 900 \mathrm{cc}, \\
\text { gasoline type) }\end{array}$ & Test range 600-3000 rpm \\
Speed sensor (rpm) & Sampling speed: approximately \\
& $5000 \mathrm{t} / \mathrm{s}$. \\
Throttle position sensor & Measurement range 0-80 \\
ADC/DAC & -10 to $10 \mathrm{VDC}, 20 \mathrm{~mA}$ \\
COMPUTER & Core2Duo: $2.93 \mathrm{GHz}, 4 \mathrm{~GB}$ \\
DC motor & RAM \\
Fuel type (experiments) & $4.8-6 \mathrm{~V}$ \\
\hline
\end{tabular}

and the dynamometer which is used to generate the loadtorque into the system. The engine speed is interpreted as the crankshaft rotation rate in revolutions per minute (rpm) and is regulated by opening the throttle. In this task, the throttle valve is directly actuated by a DC motor in which the angular movement is handled by the control signal in the form of Pulse Width Modulation (PWM). The exhaust emissions CO and $\mathrm{HC}$ were also measured through a nondispersive infrared analysis machine (Infralyt smart) in which the acquiring sampling data is $1 \mathrm{~s}$, while the fuel consumption was measured by the fuel flow sensor (Hall effect- 800 series) with the sampling period is $1 \mathrm{~ms}$. The computation unit is performed with MATLAB-Simulink programming. An ADC/DAC is used as an interface system between the computer and the real plant, while the sampling period is $1 \mathrm{~ms}$ for all experiments.
As seen in Figure 5, the desired speed is chosen to rapid change from $750 \mathrm{rpm}$ to $900 \mathrm{rpm}$ and $900 \mathrm{rpm}$ to $750 \mathrm{rpm}$, and the experiments were performed for $200 \mathrm{~s}$. This result reveals that the speed response of the proposed control scheme can reach the desired speed within short time and has no overshoot and tiny oscillation. The control input is smooth and reaches an optimal value within a short time, and the sliding variable can approach zero rapidly. Fast convergence of the response is a result of the updated control gains $\left(K_{I}\right.$ and $K_{D}$ ) of the PID controller which can be adjusted rapidly during the control process according to the adaptive law. Furthermore, the characteristic of the opening position of the throttle valve was also measured. This reveals that the motion of the actuator has smooth and tiny oscillations.

4.3. Tracking Performance and Disturbance Rejection Test. The robust properties and the tracking performance of the proposed control scheme were also assessed, because it is well known that the engine speed control is affected by the state of accessory changes such as external load disturbance [41]. In the experiments, we compare the disturbance rejection performance among the proposed controller, SMC technique, and PID controller. The load disturbance is generated by the dynamometer, while the speed set-point is chosen to be $900 \mathrm{rpm}$. Note that, for the reason of low-speed test, it is sensitive from any disturbances; therefore, the implementation in the low-speed region is more difficult than the highspeed control task. Furthermore, high performance of lowspeed control leads to increase the performance of the engine operation at any operating condition [32]. 

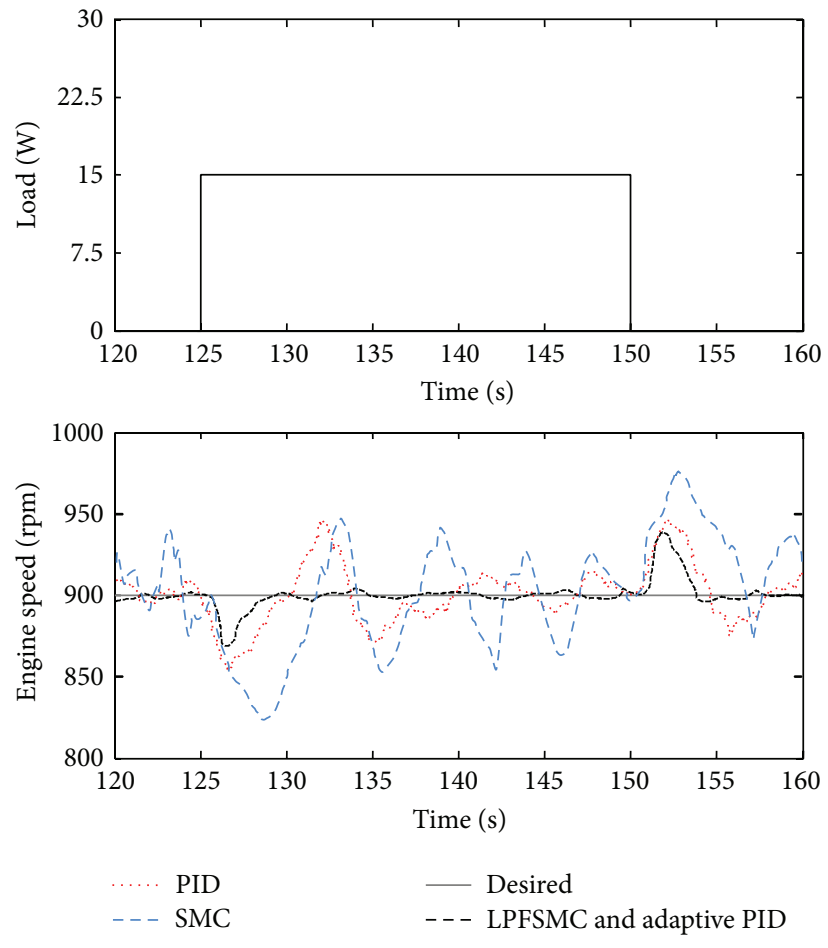

FIGURE 6: Comparisons of tracking performance and disturbance rejection of the controllers.

As seen in Figure 6, at the time $125 \mathrm{sec}$, the load torque was applied immediately into the engine speed control task. This proposed to disturb the stability of the control system at the steady-state condition. The proposed control scheme can improve the speed deviation rapidly and is capable of tracking the desired speed better than other control techniques. In addition, the load torque was decreased immediately at the time $150 \mathrm{sec}$. The results show that the proposed control scheme can decrease the speed deviation from the desired speed faster than other control techniques. The findings reveal that the proposed control scheme has effective of the robustness and fast adaptation and has better tracking performance than other control techniques.

4.4. Fuel Consumption and Exhaust Emission Investigation. In this section, the fuel consumption and the exhaust emission of the engine speed control by using the proposed control scheme and different control techniques (SMC technique and PID controller) were investigated (see Figure 7). In the experiments, the desired speed was performed for $400 \mathrm{sec}$ and was rapidly changed as shown in Figure 7(a). For the average total fuel consumption comparison (see Figure 7(b)), the proposed control scheme can attain an excellent result with the lowest averaged total fuel consumption which was obtained by the average of the fuel consumptions per second.

In addition, the average exhaust emissions were also investigated (see Figure 7(c)). The $\mathrm{CO}$ and $\mathrm{HC}$ emissions are the main pollutants contributed by the SI engines. In the principle of the combustion process of SI engine, the HC emission is appeared when fuel molecules in the engine cannot burn or burn only partially, while the $\mathrm{CO}$ emission is produced when the carbon in the fuel is partially oxidized rather than fully oxidized to carbon dioxide. However, increasing efficient strategies for engine speed control via throttle valve regulation method is capable of increasing combustion performance as it can reduce pollutant emissions also [38]. In the experiments, effects of the controllers were investigated via the constant speed set points and no adding an external engine load (small load from the unloaded hydrostatic CVT). Thus the $\mathrm{CO}_{2}$ and $\mathrm{NO}_{x}$ which are sensitive to speed variation and high temperature operation did not measure in this work (the experiments perform at coolant temperature of $70-80^{\circ} \mathrm{C}$ for short period). As a result, both averages of the $\mathrm{CO}$ and $\mathrm{HC}$ emission data were calculated by the average of emissions per second in which obtained by the direct measurement method [43]. Additionally, these results demonstrate that high fuel consumption and exhaust emission are affected by high variation of the engine speed during tracking of the set points. These results also imply that the performance of the SI engine at any operating condition can be improved by an advanced engine speed control via the electronic throttle valve regulation method, as shown in Figure 7.

\section{Conclusions}

The incorporation of the SMC and a first-order LPF with a new adaptive PID controller is proposed for tracking the control task of an uncertain nonlinear system. The controller has been successfully applied to the problem of the speed tracking control of an SI engine through electronic 


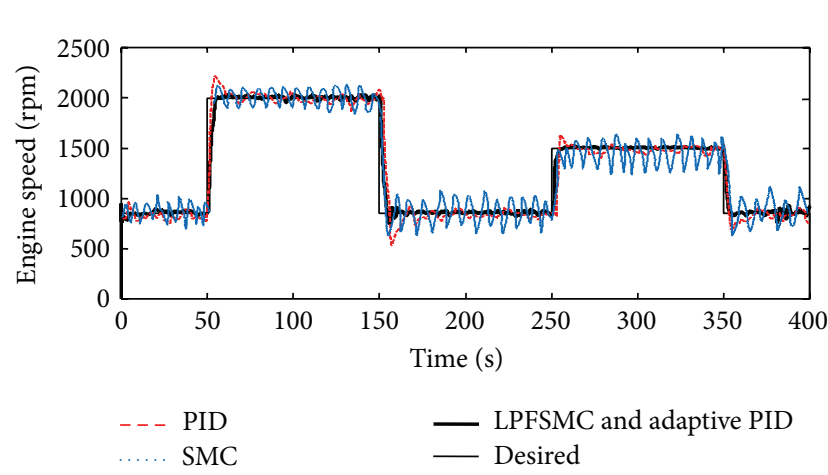

(a)

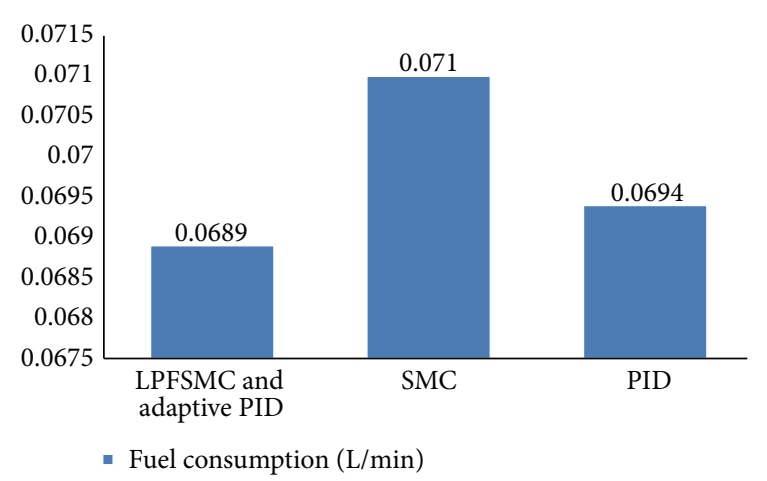

(b)

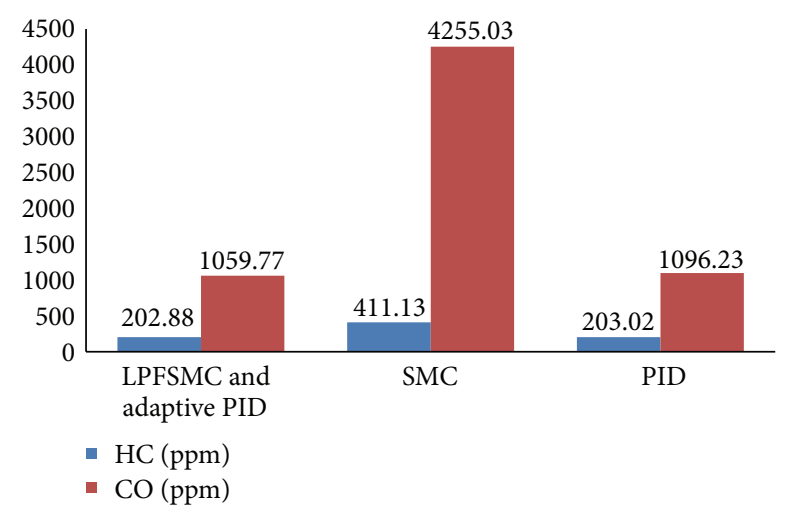

(c)

FIGURE 7: Comparisons of (a) tracking performance of the controllers; (b) fuel consumption rates; (c) exhaust emission rates.

throttle valve control architecture. From the simulation and experimental results, it achieves that

(1) the proposed adaptation law is capable of optimal online update the PID controller during the control process within a short period;

(2) the chattering of the SMC can be alleviated by a first-order low pass filter, while the robustness of the control system similar to that of the sliding mode such that the load torque disturbances can be compensated quite accurately;

(3) the proposed control scheme has high performance in implementation as it can be achieved in the problem of engine speed control in which the system is largely uncertain nonlinear system and rather complex mechanisms.

\section{Conflict of Interests}

The authors have no competing interests.

\section{Acknowledgment}

This research is financially supported by the Office of Research Administration (ORA) and Farm Engineering and Automation Technology Research Group (FEAT) of Khon
Kaen University, Thailand. The authors are also thankful to the reviewers and Mr. Ian Thomas for their valuable comments and suggestions for English grammar correction, respectively.

\section{References}

[1] K.-C. Hsu, W.-Y. Wang, and P.-Z. Lin, "Sliding mode control for uncertain nonlinear systems with multiple inputs containing sector nonlinearities and deadzones," IEEE Transactions on Systems, Man, and Cybernetics, Part B: Cybernetics, vol. 34, no. 1, pp. 374-380, 2004.

[2] G. Bartolini and A. Ferrara, "Multi-input sliding mode control of a class of uncertain nonlinear systems," IEEE Transactions on Automatic Control, vol. 41, no. 11, pp. 1662-1666, 1996.

[3] T.-C. Kuo, Y.-J. Huang, and S.-H. Chang, "Sliding mode control with self-tuning law for uncertain nonlinear systems," ISA Transactions, vol. 47, no. 2, pp. 171-178, 2008.

[4] G. Montaseri and M. J. Yazdanpanah, "Predictive control of uncertain nonlinear parabolic PDE systems using a Galerkin/ neural-network-based model," Communications in Nonlinear Science and Numerical Simulation, vol. 17, no. 1, pp. 388-404, 2012.

[5] F. O. Tellez, A. G. Loukianov, E. N. Sanchez, and E. Jose Bayro Corrochano, "Decentralized neural identification and control for uncertain nonlinear systems: application to planar robot," Journal of the Franklin Institute, vol. 347, no. 6, pp. 1015-1034, 2010. 
[6] A. Bazaei and V. J. Majd, "Feedback linearization of discretetime nonlinear uncertain plants via first-principles-based serial neuro-gray-box models," Journal of Process Control, vol. 13, no. 8, pp. 819-830, 2003.

[7] T.-Y. Kuc and W.-G. Han, "An adaptive PID learning control of robot manipulators," Automatica, vol. 36, no. 5, pp. 717-725, 2000.

[8] Y. Pan, Y. Zhou, T. Sun, and M. J. Er, "Composite adaptive fuzzy $H_{\infty}$ tracking control of uncertain nonlinear systems," Neurocomputing, vol. 99, pp. 15-24, 2013.

[9] X. Liu, R. Tao, and M. Tavakoli, "Adaptive control of uncertain nonlinear teleoperation systems," Mechatronics, vol. 24, no. 1, pp. 66-78, 2014.

[10] W.-D. Chang and J.-J. Yan, "Adaptive robust PID controller design based on a sliding mode for uncertain chaotic systems," Chaos, Solitons \& Fractals, vol. 26, no. 1, pp. 167-175, 2005.

[11] T. C. Kuo, Y. J. Huang, C. Y. Chen, and C. H. Chang, "Adaptive sliding mode control with PID tuning for uncertain system," Engineering Letters, vol. 16, no. 3, pp. 1-5, 2008.

[12] M. N. Howell and M. C. Best, "On-line PID tuning for engine idle-speed control using continuous action reinforcement learning automata," Control Engineering Practice, vol. 8, no. 2, pp. 147-154, 2000.

[13] C.-F. Hsu and B.-K. Lee, "FPGA-based adaptive PID control of a DC motor driver via sliding-mode approach," Expert Systems with Applications, vol. 38, no. 9, pp. 11866-11872, 2011.

[14] D. W. Memering and P. H. Meckl, "Comparison of adaptive control techniques applied to diesel engine idle speed regulation," Journal of Dynamic Systems, Measurement and Control, vol. 124, no. 4, pp. 682-688, 2002.

[15] V. I. Utkin, "Sliding mode control design principles and applications to electric drives," IEEE Transactions on Industrial Electronics, vol. 40, no. 1, pp. 23-36, 1993.

[16] Y. J. Huang and T. C. Kuo, "Robust output tracking control for nonlinear time-varying robotic manipulators," Electrical Engineering, vol. 87, no. 1, pp. 47-55, 2005.

[17] M. Hajatipour and M. Farrokhi, "Chattering free with noise reduction in sliding-mode observers using frequency domain analysis," Journal of Process Control, vol. 20, no. 8, pp. 912-921, 2010.

[18] A. Sabanovic, L. Fridman, and S. Spurgeon, Variable Structure Systems: From Principles to Implementation, The Institution of Engineering and Technology, 2004.

[19] Y. Xu, "Chattering free robust control for nonlinear systems," IEEE Transactions on Control Systems Technology, vol. 16, no. 6, pp. 1352-1359, 2008.

[20] H. Lee and V. I. Utkin, "Chattering suppression methods in sliding mode control systems," Annual Reviews in Control, vol. 31, no. 2, pp. 179-188, 2007.

[21] Y. Ren, Z. Liu, L. Chang, and N. Wen, "Adaptive sliding mode robust control for virtual compound-axis servo system," Mathematical Problems in Engineering, vol. 2013, Article ID 343851, 9 pages, 2013.

[22] M.-L. Tseng and M.-S. Chen, "Chattering reduction of sliding mode control by low-pass filtering the control signal," Asian Journal of Control, vol. 12, no. 3, pp. 392-398, 2010.

[23] H. Sira-RamÍRez, "On the dynamical sliding mode control of nonlinear systems," International Journal of Control, vol. 57, no. 5, pp. 1039-1061, 1993.

[24] J.-X. Xu, Y.-J. Pan, and T.-H. Lee, "Sliding mode control with closed-loop filtering architecture for a class of nonlinear systems," IEEE Transactions on Circuits and Systems II: Express Briefs, vol. 51, no. 4, pp. 168-173, 2004.

[25] A. Deenadayalan and G. S. Ilango, "Position sensorless sliding mode observer with sigmoid function for Brushless DC motor," in Proceedings of the International Conference on Advances in Power Conversion and Energy Technologies (APCET '12), pp. 1-6, IEEE, August 2012.

[26] Y. Xia, X. Yu, and W. Oghanna, "Adaptive robust fast control for induction motors," IEEE Transactions on Industrial Electronics, vol. 47, no. 4, pp. 854-862, 2000.

[27] M. Niclai, Theory of Nonlinear Control Systems, McGraw-Hill, 1969.

[28] J. J. Slotine and W. Li, Applied Nonlinear Control, Prentice-Hall, Englewood Cliffs, NJ, USA, 1991.

[29] D. Gorinevsky and L. A. Feldkamp, "RBF network feedforward compensation of load disturbance in idle speed control," IEEE Control Systems, vol. 16, no. 6, pp. 18-27, 1996.

[30] S. Di Cairano, D. Yanakiev, A. Bemporad, I. V. Kolmanovsky, and D. Hrovat, "Model predictive idle speed control: design, analysis, and experimental evaluation," IEEE Transactions on Control Systems Technology, vol. 20, no. 1, pp. 84-97, 2012.

[31] P. F. Puleston, S. Spurgeon, and G. Monsees, "Automotive engine speed control: a robust nonlinear control framework," IEE Proceedings: Control Theory and Applications, vol. 148, no. 1, pp. 81-87, 2001.

[32] Y. Yildiz, A. M. Annaswamy, D. Yanakiev, and I. Kolmanovsky, "Spark-ignition-engine idle speed control: an adaptive control approach," IEEE Transactions on Control Systems Technology, vol. 19, no. 5, pp. 990-1002, 2011.

[33] A. Sugeng, K. Baharin, T. Hishamuddin, and J. B. Supriyo, "Engine speed control using online ANN for vehicle with EMDAP-CVT," Jurnal Mekanikal, vol. 22, pp. 39-52, 2006.

[34] M. K. Khan, K. B. Goh, and S. K. Spurgeon, "Second order sliding mode control of a diesel engine," Asian Journal of Control, vol. 5, no. 4, pp. 614-619, 2003.

[35] J. R. Wagner, D. M. Dawson, and L. Zeyu, "Nonlinear air-tofuel ratio and engine speed control for hybrid vehicles," IEEE Transactions on Vehicular Technology, vol. 52, no. 1, pp. 184-195, 2003.

[36] F. Assadian, S. Fekri, and M. Hancock, "Hybrid electric vehicles challenges: strategies for advanced engine speed control," in Proceedings of the IEEE International Electric Vehicle Conference (IEVC '12), March 2012.

[37] A. G. Ulsoy, H. Peng, and M. Çakmakci, Automotive Control Systems, Cambridge University Press, Cambridge, UK, 2014.

[38] C. Ji and S. Wang, "Strategies for improving the idle performance of a spark-ignited gasoline engine," International Journal of Hydrogen Energy, vol. 37, no. 4, pp. 3938-3944, 2012.

[39] S. Wang, C. Ji, M. Zhang, and B. Zhang, "Reducing the idle speed of a spark-ignited gasoline engine with hydrogen addition," International Journal of Hydrogen Energy, vol. 35, no. 19, pp. 10580-10588, 2010.

[40] D. Hrovat and J. Sun, "Models and control methodologies for IC engine idle speed control design," Control Engineering Practice, vol. 5, no. 8, pp. 1093-1100, 1997.

[41] B. Alt, J. P. Blath, F. Svaricek, and M. Schultalbers, "Multiple sliding surface control of idle engine speed and torque reserve with dead start assist control," IEEE Transactions on Industrial Electronics, vol. 56, no. 9, pp. 3580-3592, 2009. 
[42] T. Radpukdee and P. Jirawattana, "Uncertainty learning and compensation: an application to pressure tracking of an electrohydraulic proportional relief valve," Control Engineering Practice, vol. 17, no. 2, pp. 291-301, 2009.

[43] P. A. Loannou and J. Sun, Robust Adaptive Control, PTR Prentice-Hall, 1996.

[44] C. D. Richard and H. B. Robert, Modern Control Systems, Prentice Hall, Upper Saddle River, NJ, USA, 2011.

[45] A. Jansri and P. Sooraksa, "Enhanced model and fuzzy strategy of air to fuel ratio control for spark ignition engines," Computers \& Mathematics with Applications, vol. 64, no. 5, pp. 922-933, 2012.

[46] Z. Ye, "Modeling, identification, design, and implementation of nonlinear automotive idle speed control systems-an overview," IEEE Transactions on Systems, Man and Cybernetics Part C: Applications and Reviews, vol. 37, no. 6, pp. 1137-1151, 2007. 


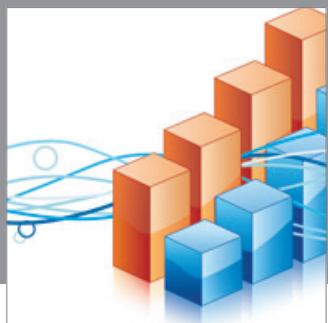

Advances in

Operations Research

mansans

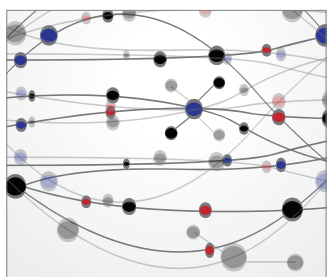

The Scientific World Journal
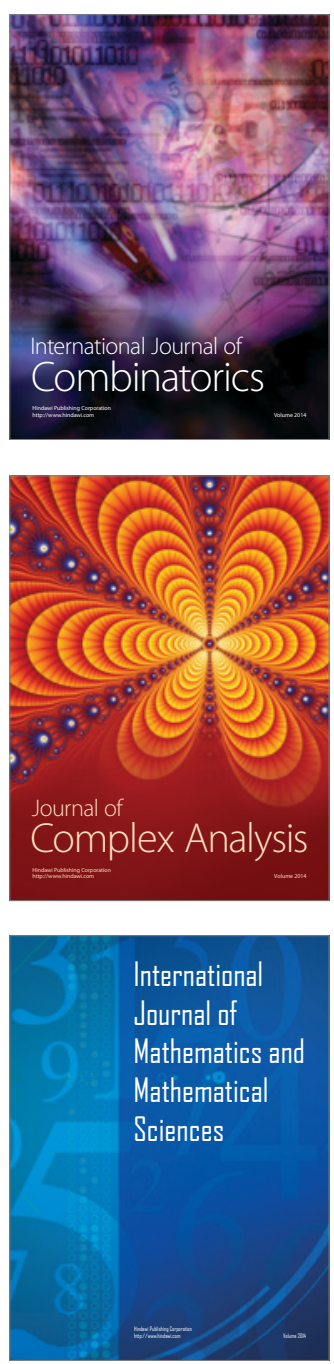
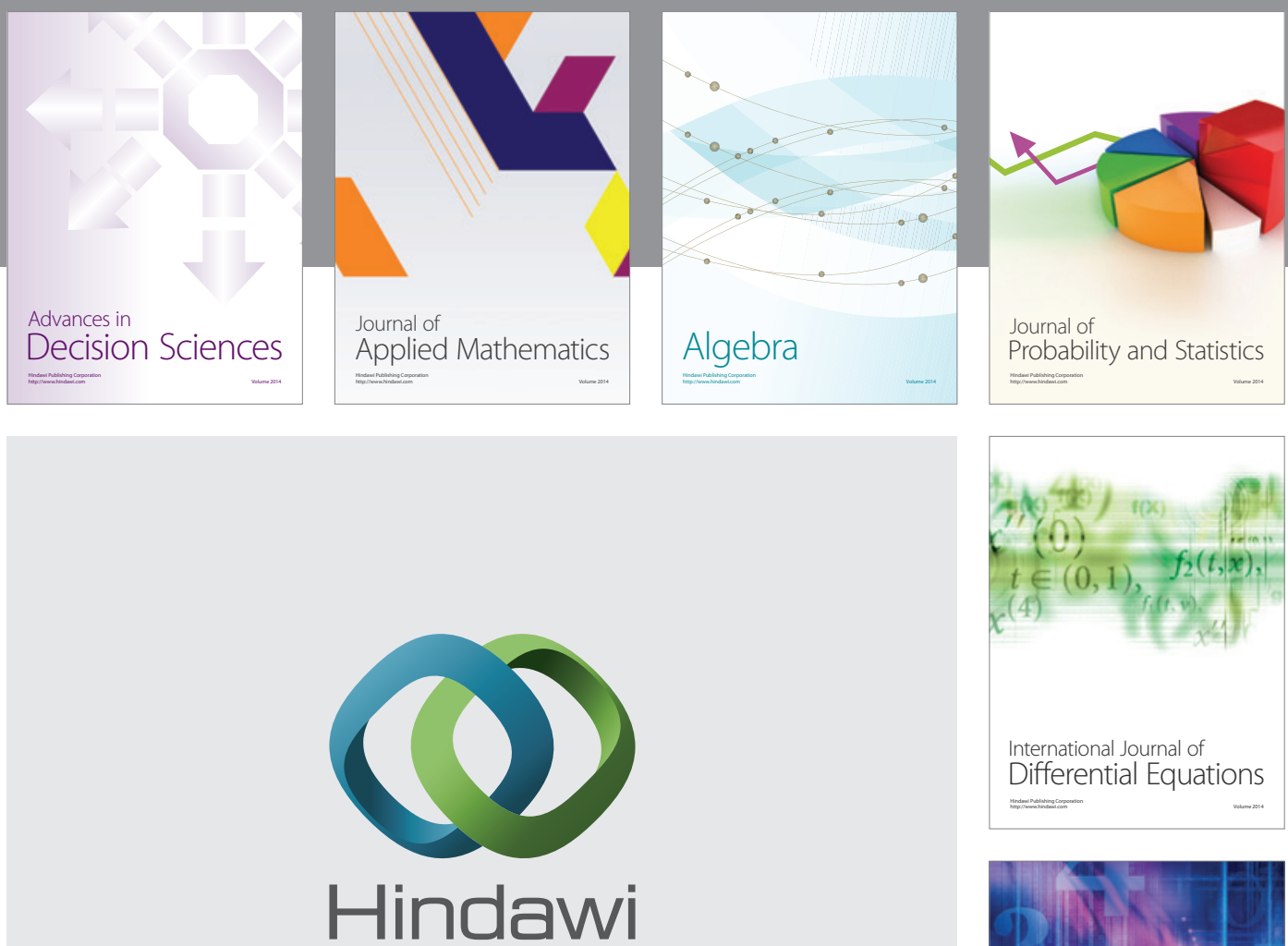

Submit your manuscripts at http://www.hindawi.com
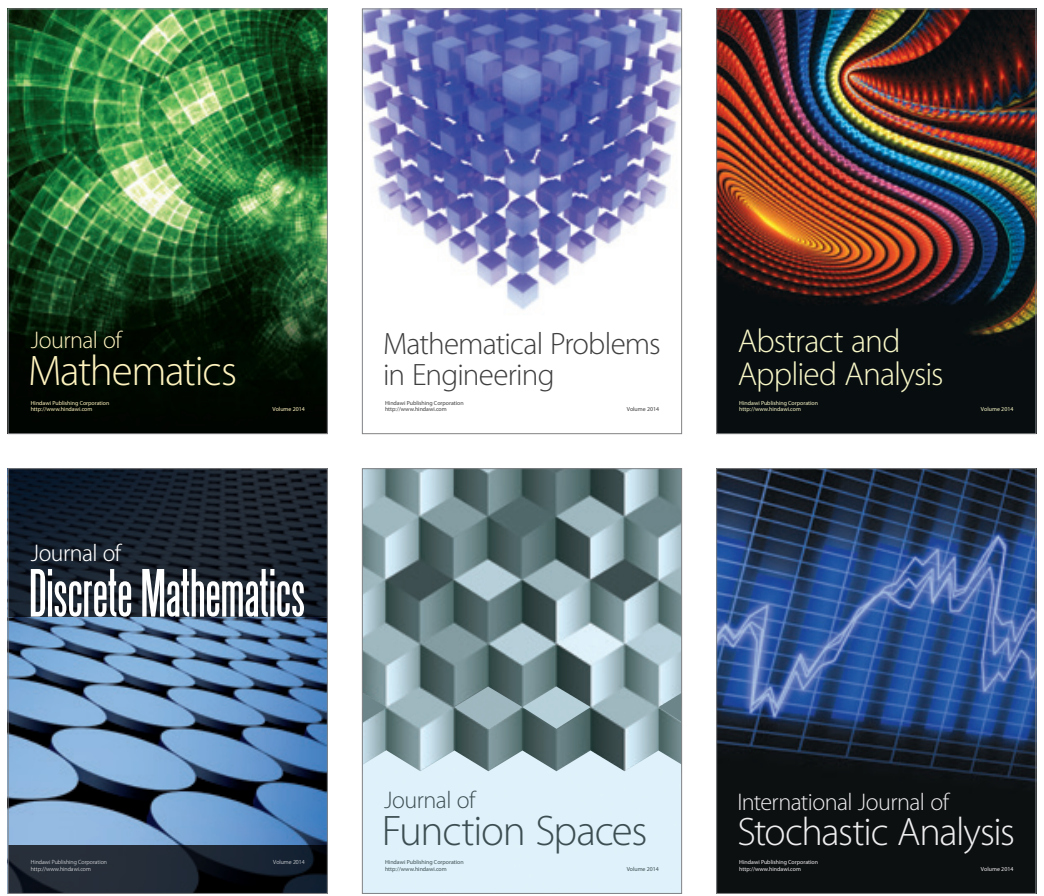

Journal of

Function Spaces

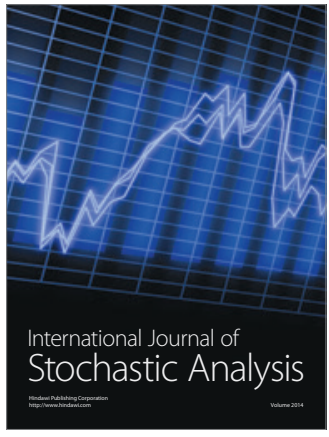

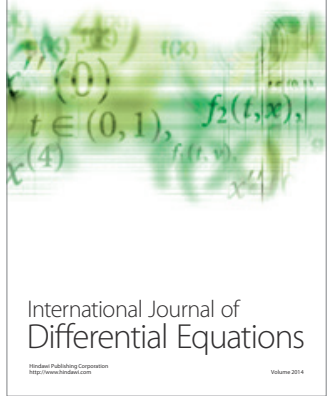
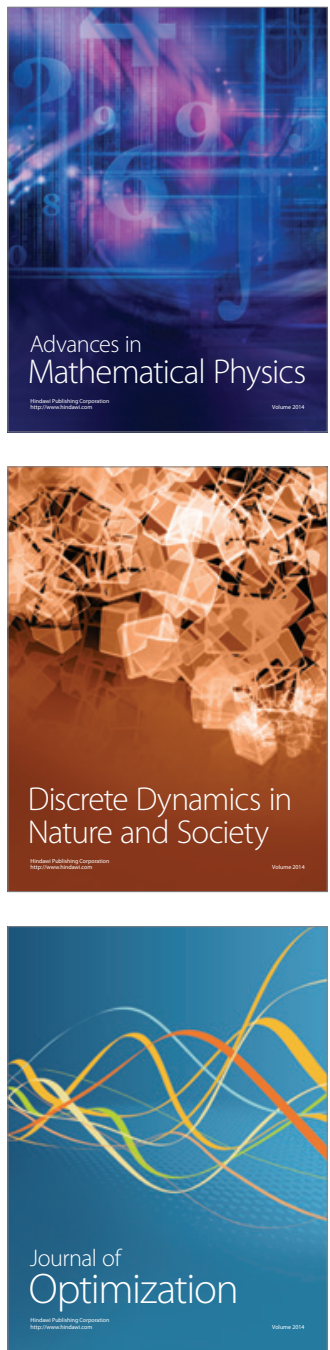